\title{
The Amyloid Phenomenon and Its Significance in Biology and Medicine
}

\author{
Christopher M. Dobson, Tuomas P.J. Knowles, and Michele Vendruscolo \\ Centre for Misfolding Diseases, Department of Chemistry, University of Cambridge, Cambridge CB2 1EW, \\ United Kingdom \\ Correspondence: cmd44@cam.ac.uk; tpjk2@cam.ac.uk; mv245@cam.ac.uk
}

\begin{abstract}
The misfolding of proteins is now recognized to be the origin of a large number of medical disorders. One particularly important group of such disorders is associated with the aggregation of misfolded proteins into amyloid structures, and includes conditions ranging from Alzheimer's and Parkinson's diseases to type II diabetes. Such conditions already affect over 500 million people in the world, a number that is rising rapidly, and at present these disorders cannot be effectively treated or prevented. This review provides an overview of this field of science and discusses recent progress in understanding the nature and properties of the amyloid state, the kinetics and mechanism governing its formation, the origins of its links with disease, and the manner in which its formation may be inhibited or suppressed. This latter topic is of particular importance, both to enhance our knowledge of the maintenance of protein homeostasis in living organisms and also to address the development of therapeutic strategies through which to combat the loss of homeostasis and the associated onset and progression of disease.
\end{abstract}

$\mathrm{N}$ atural proteins are a highly select group of molecules, and their properties have a number of very special characteristics when compared with random sequences of amino acids, including an ability to fold into unique and often highly intricate structures that can remain functional within the complex milieu of living systems (Dobson 2003; Robinson et al. 2007). Such characteristics have enabled biological systems to develop a vast range of functions and with an astonishing degree of specificity. Because proteins are involved in virtually every chemical process taking place within the cellular environment; however, the failure of these molecules to fold correctly or to remain within their functional states can give rise to serious cellular malfunctions (Dobson 2003; Eisenberg and Jucker 2012; Knowles et al. 2014; Chiti and Dobson 2017). Protein misfolding was until relatively recently considered to be a rather esoteric topic except in the context of problems associated with protein production for biotechnological purposes, and of its links with a small number of rather uncommon diseases. This situation has, however, now changed dramatically as misfolding diseases are rapidly becoming the most prevalent and disruptive in terms of health and medical care in the modern world (Chiti and Dobson 2017; World Alzheimer Report 2018).

Editors: Richard I. Morimoto, F. Ulrich Hartl, and Jeffery W. Kelly

Additional Perspectives on Protein Homeostasis available at www.cshperspectives.org

Copyright (C) 2020 Cold Spring Harbor Laboratory Press; all rights reserved; doi: 10.1101/cshperspect.a033878

Cite this article as Cold Spring Harb Perspect Biol 2020;12:a033878 
Of particular importance are those disorders in which misfolding results in the conversion through aggregation of normally soluble proteins into intractable and highly stable amyloid structures (Table 1; Eisenberg and Jucker 2012; Dobson 2013; Knowles et al. 2014; Chiti and Dobson 2017). The increase in the significance of this group of diseases results primarily because many of these conditions are strongly associated with aging-notably Alzheimer's disease-and with lifestyle and dietary changes-notably type II diabetes - and because they are currently incurable and largely untreatable. In addition, however, it is now recognized that the study of the process of amyloid formation has profound significance for understanding normal as well as aberrant biological phenomena, and indeed for the generation of important new biomaterials with novel and interesting properties (Knowles and Buehler 2011; Shimanovich et al. 2015; Wei et al. 2017). In this review, we will discuss our increasing knowledge of the amyloid state of proteins, with particular emphasis on the kinetics of its formation, in terms of the mechanisms by which aggregation occurs and can be controlled, and of the significance of such knowledge in the fields of biological and medical sciences.

\section{THE AMYLOID STATE OF PROTEINS}

The amyloid state of a protein typically has the form of threadlike fibrils a few nanometers in diameter and frequently microns in length (Fig. 1; Sunde et al. 1997; Jiménez et al. 2002; Nelson et al. 2005; Eisenberg and Jucker 2012). Regardless of the amino acid sequence, or indeed of the structure of the protein in its native state, such fibrils are rich in $\beta$-sheet patterns and are closely packed and highly ordered. Although amyloid structures were originally observed in the context of disease, experiments with a wide range of peptides and proteins in laboratory environments have led to the realization that the ability to form such aggregated states is not a rare phenomenon associated with a small number of disease-related proteins; instead, the amyloid state appears as an alternative well-defined structural form that can be adopted by many, if not all, polypeptide sequences under appropriate condi- tions, including those of proteins whose native states are globular or intrinsically disordered, and that are cytosolic or membrane bound (Dobson 2003).

Unlike the native states of proteins, however, amyloid fibrils possess a core region having a common or "generic" cross- $\beta$ architecture (Sunde et al. 1997; Dobson 2003; Eisenberg and Jucker 2012) that is dictated by the properties of the polypeptide backbone, rather than encoded by its sequence, although their propensity to form, and their detailed structures and properties, varies significantly with the amino acid composition and sequence (Fändrich and Dobson 2002; Pawar et al. 2005). Moreover, it is increasingly clear that the amyloid state, particularly for small proteins or proteolytic fragments of larger proteins, with $<150$ residues, can be thermodynamically more stable than the functional native states even under normal physiological conditions (Gazit 2002; Baldwin et al. 2011). The familiar functional forms of proteins, therefore, do not always represent the global minima on the free energy surfaces defined by their specific polypeptide sequences, but rather can be metastable states that are separated from the amyloid form by high kinetic barriers.

These observations show that biological systems have evolved to enable their functional proteins to remain in solution, or sequestered in membranes, often for prolonged lengths of time under physiological conditions, rather than aggregating and ultimately converting into the amyloid state, except in the relatively small number of cases in which this latter form of protein structure is used functionally, for purposes ranging from structural templates to mechanisms of storage (Fowler et al. 2007; Maji et al. 2009). Some of the kinetic barriers that maintain proteins in solution in their native states are encoded in their sequences, notably through folding into highly cooperative structures with aggregation-prone regions buried in their internal regions (Broome and Hecht 2000; Dobson 2003) and the avoidance of patterns of residues that would favor the amyloid state, for example by stabilizing $\beta$-sheet structures (Broome and Hecht 2000; Tartaglia et al. 2008). There is evidence as well that the large size of many protein 
Amyloid Phenomenon in Biology and Medicine

Table 1. Selection of human diseases associated with protein misfolding and the formation of extracellular amyloid deposits or intracellular inclusions with amyloid-like characteristics

\begin{tabular}{|c|c|c|c|}
\hline Disease & $\begin{array}{l}\text { Aggregating protein } \\
\text { or peptide }\end{array}$ & $\begin{array}{l}\text { Length of protein or } \\
\text { peptide }^{\mathrm{a}}\end{array}$ & $\begin{array}{l}\text { Structure of protein } \\
\text { or peptide }\end{array}$ \\
\hline \multicolumn{4}{|l|}{ Neurodegenerative diseases } \\
\hline \multirow[t]{2}{*}{ Alzheimer's disease ${ }^{c}$} & Amyloid- $\beta$ peptide & $37-48^{\mathrm{f}}$ & Intrinsically disordered \\
\hline & Tau protein & $352-441$ & Intrinsically disordered \\
\hline $\begin{array}{l}\text { Spongiform } \\
\text { encephalopathies }^{\mathrm{c}, \mathrm{e}}\end{array}$ & Prion protein or fragments & 230 & $\begin{array}{l}\text { Intrinsically disordered } \\
\text { and } \alpha \text {-helical }\end{array}$ \\
\hline Parkinson's disease ${ }^{c}$ & $\alpha$-Synuclein & 140 & Intrinsically disordered \\
\hline $\begin{array}{l}\text { Amyotrophic lateral } \\
\text { sclerosis }^{c}\end{array}$ & Superoxide dismutase 1 & 154 & $\beta$-sheet and Ig-like \\
\hline Huntington's disease $^{\mathrm{d}}$ & Fragments of huntingtin 1 & $103-187^{\mathrm{g}}$ & $\begin{array}{l}\text { Largely intrinsically } \\
\text { disordered }\end{array}$ \\
\hline $\begin{array}{l}\text { Familial amyloid } \\
\text { polyneuropathy }^{\mathrm{d}}\end{array}$ & Mutants of transthyretin & 127 & $\beta$-Sheet \\
\hline \multicolumn{4}{|c|}{ Nonneuropathic systemic amyloidoses } \\
\hline AL amyloidosis ${ }^{c}$ & $\begin{array}{l}\text { Immunoglobulin light chains } \\
\text { or fragments thereof }\end{array}$ & $100^{\mathrm{f}}$ & $\beta$-Sheet Ig-like \\
\hline AA amyloidosis ${ }^{c}$ & $\begin{array}{l}\text { Fragments of serum amyloid } \\
\text { A protein }\end{array}$ & $45-104^{\mathrm{f}}$ & $\begin{array}{l}\alpha \text {-Helical and unknown } \\
\text { fold }\end{array}$ \\
\hline Senile systemic amyloidosis ${ }^{c}$ & Wild-type transthyretin & 127 & $\beta$-Sheet \\
\hline $\begin{array}{l}\text { Hemodialysis-related } \\
\text { amyloidosis }^{c}\end{array}$ & $\beta 2$-Microglobulin & 99 & $\beta$-Sheet and Ig-like \\
\hline Lysozyme amyloidosis $^{\mathrm{d}}$ & Mutants of lysozyme & 130 & $\alpha$-Helical and $\beta$-sheet \\
\hline \multicolumn{4}{|c|}{ Nonneuropathic localized amyloidoses } \\
\hline Apo A-I amyloidosis ${ }^{\mathrm{d}}$ & $\begin{array}{l}\text { Fragments of apolipoprotein } \\
\text { A-I }\end{array}$ & $69-100^{\mathrm{f}}$ & Intrinsically disordered \\
\hline Type II diabetes $^{c}$ & Amylin (IAPP) & 37 & Intrinsically disordered \\
\hline $\begin{array}{l}\text { Medullary carcinoma of the } \\
\text { thyroid }^{c}\end{array}$ & Calcitonin & 32 & Intrinsically disordered \\
\hline $\begin{array}{l}\text { Injection-localized } \\
\text { amyloidosis }^{c}\end{array}$ & Insulin & $21+30^{\mathrm{h}}$ & $\alpha$-Helical \\
\hline
\end{tabular}

From Dobson 2013; adapted, with permission. A more comprehensive list is given in Chiti and Dobson 2017.

Ig, Immunoglobulin; AL, amyloid light chain; AA, serum amyloid A protein; Apo A-I, apolipoprotein A-I; IAPP, islet amyloid polypeptide.

${ }^{\mathrm{a}}$ Data do not refer to the number of amino acid residues of the precursor proteins, but to the lengths of the processed polypeptide chains that are present in the aggregates that are deposited in the disease states.

${ }^{\mathrm{b}}$ This column reports the structural class and general native fold; both refer to the processed peptides or proteins that deposit into aggregates before aggregation and not to the precursor proteins.

${ }^{c}$ Predominantly sporadic, although in some of these diseases hereditary forms associated with specific mutations are well documented.

${ }^{\mathrm{d}}$ Predominantly hereditary, although in some of these diseases sporadic cases are well documented.

${ }^{\mathrm{e}} 5 \%$ of cases are infectious (iatrogenic).

${ }^{\mathrm{f}}$ Fragments of various lengths are generated and reported in ex vivo fibrils.

${ }^{\mathrm{g}}$ Lengths refer to the normal sequences with nonpathogenic traits of polyglutamine (poly[Q]).

${ }^{\mathrm{h}}$ Human insulin consists of two chains (A and B with 21 and 30 residues, respectively) covalently bonded by disulfide bridges. 
C.M. Dobson et al.

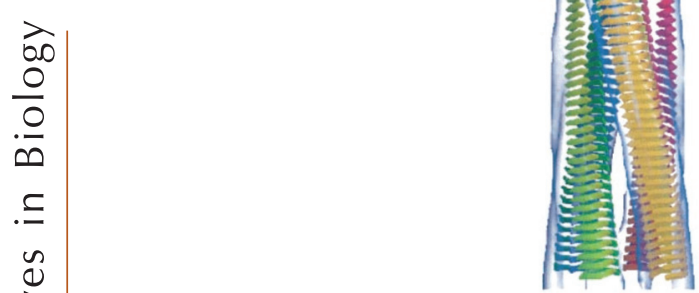

Figure 1. Model of one of the polymorphs of the amyloid fibrils formed from insulin as defined from cryogenic electron microscopy (cryo-EM) analysis. This particular fibril contains four protofilaments that twist around each other to form the mature fibril. Each of the protofilaments has a pair of nearly flat $\beta$ sheets, with the component strands oriented perpendicularly to the main fibril axis. (From Jiménez et al. 2002; reprinted, with permission, from the National Academy of Sciences (c) 2002.)

molecules is likely to disfavor their assembly into polymeric amyloid structures relative to folded native states (Baldwin et al. 2011).

More generally, proteins and indeed other biomolecules have coevolved with their biological environments, and factors ranging from localization in cellular compartments to the regulation of synthesis and degradation, and the existence of molecular chaperones, act to limit the probability of the formation and accumulation of misfolded and aggregated peptides and proteins (Morimoto 2008; Hartl et al. 2011; Vendruscolo et al. 2011). Indeed, proteins can adopt a multiplicity of states following their synthesis (Fig. 2) and such mechanisms ensure in a properly functional organism that the right state of a given protein is present at the right time and in the right place, much as enzymes control the nature, location, and populations of small mol- ecules, for example in the regulation of metabolic processes (Knowles et al. 2014). It is increasingly clear, however, that as proteins begin to aggregate such protective mechanisms can become inadequate and ultimately result in a widespread loss of protein homeostasis (Balch et al. 2008; Morimoto 2008; Hartl et al. 2011; Vendruscolo et al. 2011; Labbadia and Morimoto 2015).

\section{THE KINETICS AND MECHANISM OF AMYLOID FORMATION}

In the light of the importance of the rates at which specific proteins aggregate to form the amyloid state, a key step in understanding its occurrence in given environments is to define the mechanisms by which it is generated. Amyloid fibrils are typically composed of a number of protofilaments that twist around each other, the core of each adopting a cross- $\beta$ structure in which $\beta$ strands are oriented perpendicularly to the fibril axis to create hydrogen-bonded $\beta$-sheets running along its length; such structural features make the structures extremely stable, both thermodynamically and kinetically, and also resistant to degradation by proteolytic enzymes or other mechanisms (Knowles et al. 2007, 2014).

Methodological developments in X-ray crystallography (Wei et al. 2017), solid-state nuclear magnetic resonance (NMR) spectroscopy (Petkova et al. 2002; Colvin et al. 2015), and cryogenic electron microscopy (cryo-EM) techniques (Sunde et al. 1997; Sachse et al. 2008; Fitzpatrick et al. 2017), have resulted in a steady increase in our detailed knowledge of the molecular structures of amyloid fibrils, including those of fibrillar deposits extracted from diseased human brain tissue (Fitzpatrick et al. 2017). The structures formed from different proteins, and under different conditions, differ both in the manner in which the various side chains are incorporated into the overall architecture of the fibrillar state and in the way specific regions of the polypeptide chain are brought together to form the cross- $\beta$ cores that are characteristic of the amyloid state. Such differences, in particular in the case of prions, have been related to the various "strains" of disease, and it is likely that 

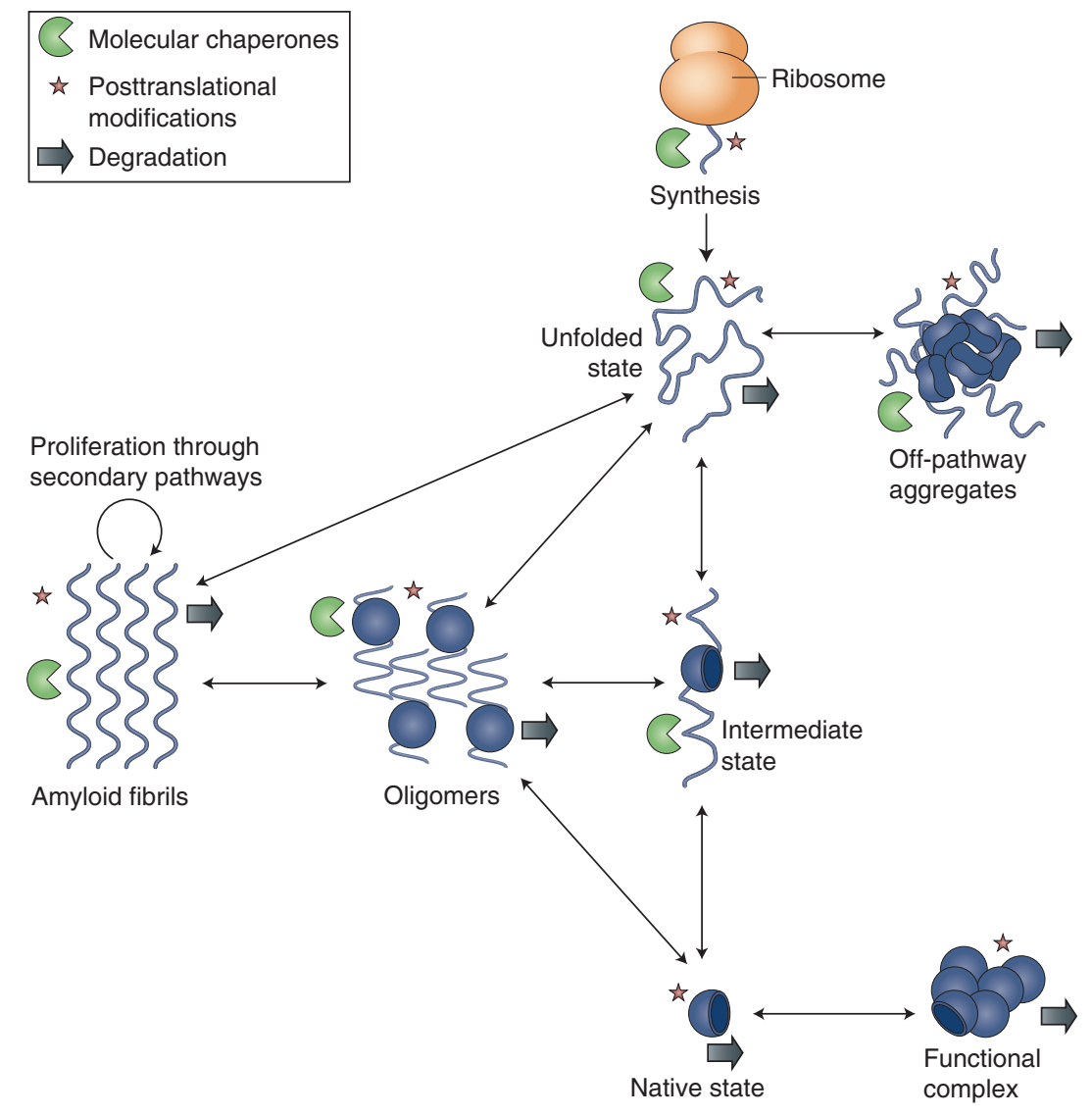

Figure 2. The different states of a protein and the process of their interconversion. Schematic description of a selection of the possible states that can be formed by proteins under different circumstances. The populations and their rates of interconversion are determined by their different thermodynamic stabilities and free energy barriers associated with the various transitions as well as by the rates of synthesis and degradation, the propensity to interact with molecular chaperones, and to undergo posttranslational and other chemical modifications such as proteolytic cleavage. (From Knowles et al. 2014; reprinted, with permission, from Springer Nature @ 2014 .)

other amyloid structures also have structures characteristic of specific manifestations of disease within individual patients (Safar et al. 1998; Petkova et al. 2005).

A wide variety of studies has shown that the process of conversion from a soluble, typically monomeric, state of a protein into the polymeric fibrillar state involves a series of well-defined molecular steps and a variety of intermediate species. Moreover, it is increasingly clear that these elementary steps operate together to give rise to a complex phenomenology and a range of associative, dissociative, and rearrangement events taking place during the course of the pro- cess that culminates in the formation of mature fibrils (Michaels et al. 2018). Our understanding of the nature of these intermediate species and the kinetics and mechanisms of their formation and interconversion has increased dramatically in recent years as a result of careful experimental studies coupled to the application of mathematical methods of analysis (Knowles et al. 2009; Cohen et al. 2013; Meisl et al. 2016; Michaels et al. 2018). These advances have allowed the framework of microscopic rate laws and chemical kinetics to be used quantitatively in the area of protein aggregation studies and to relate macroscopic measurements of aggregation behavior 
C.M. Dobson et al.

to the fundamental molecular level processes and their rates. In particular, these methods have revealed that the macroscopic observations of the time dependence of fibril formation, measured, for example, by the intensity of the fluorescence of the amyloid-specific dye thioflavin $\mathrm{T}$, are the result of a network of distinct microscopic steps, including primary and secondary nucleation and other processes such as fragmentation and elongation of the filamentous structures (Fig. 3; Knowles et al. 2009; Cohen et al. 2013; Meisl et al. 2016; Michaels et al. 2018).

These different microscopic processes depend in characteristic ways on variables such as concentration and the presence of specific quantities of preformed fibrils (seeding), and systematic variations in these conditions can enable the network of contributing microscopic processes to be analyzed to define their rate constants and relative significance (Knowles et al. 2009; Cohen et al. 2013; Meisl et al. 2016; Michaels et al. 2018). One of the most interesting results from such kinetic analysis has been the finding of the importance of secondary nucleation in the mechanism of the aggregation of the 40 and 42 residue $A \beta$-peptides that are linked to Alzheimer's disease (Cohen et al. 2013; Meisl et al. 2016; Törnquist et al. 2018). Secondary nucleation is a process generating new fibrils from monomeric precursor proteins that is catalyzed on the surfaces of aggregated species, a process that generates positive feedback as the number of fibrils in turn increases the available catalytic surface and hence results in their rapid proliferation (Cohen et al. 2013; Michaels et al. 2018; Törnquist et al. 2018). Other biological surfaces in addition to those of amyloid fibrils can also catalyze the nucleation step in amyloid formation. Indeed, studies of other systems, show that differences exist in the relative importance of specific steps; in the case of $\alpha$-synuclein, whose aggregation is linked to Parkinson's disease, primary nucleation has been found to be a key process that is enhanced very significantly by the surfaces of the lipid bilayers that are the major components of cell membranes (Galvagnion et al. 2015). In other systems, notably both yeast and mammalian prions, fibril multiplication through fragmentation processes appears to be of particular significance in the proliferation of aggregates (Aguzzi and Calella 2009; Knowles et al. 2009).

Further information about the nature and properties of the species formed during the aggregation process has come from the concerted application of a series of experimental techniques, including the measurement of their sizes and structural characteristics by single-molecule optical methods (Cremades et al. 2012), and

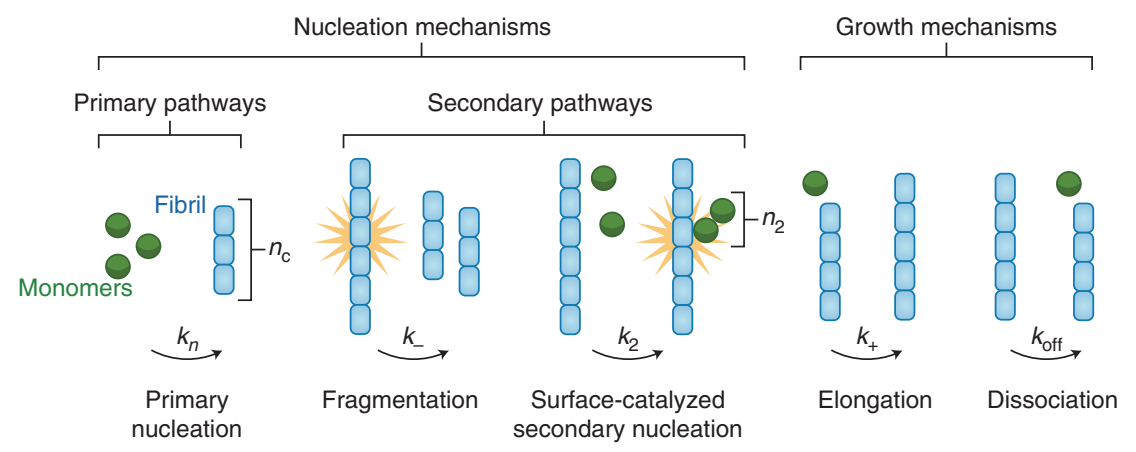

Figure 3. The microscopic steps that can contribute to the macroscopic conversion of soluble proteins into amyloid fibrils. The mechanisms of these microscopic steps can be divided into nucleation (i.e., fibril-forming) and growth processes. Events producing new fibrils are further classified as primary or secondary processes on the basis of their dependence (secondary) or lack of dependence ( primary) on the population of aggregates. Here, $k_{n}$, $k_{-}, k_{+}$, and $k_{\text {off }}$ represent rate constants, and $n_{\mathrm{c}}$ and $n_{2}$ represent the reaction orders of primary and secondary (surface-catalyzed) nucleation. (From Michaels et al. 2018; reprinted, with permission, from Annual Reviews ()) 2018.) 
their diffusion properties by microfluidics (Knowles et al. 2011). The latter properties are of particular interest not just in understanding the fundamental mechanism of aggregation but also the ability of the component species to proliferate spatially and to promote further aggregation (Herling et al. 2018). Although such measurements have primarily been made under laboratory conditions, it is possible to relate them to the events occurring in living systems (Luheshi et al. 2008; Kundel et al. 2018), and some biophysical techniques, for example those involving fluorescence measurements, can be used to study the aggregation process directly within living systems and hence to compare the events occurring in different environments (Kaminski et al. 2011).

\section{THE BIOLOGICAL CONSEQUENCES OF AMYLOID FORMATION}

The presence of amyloid deposits in a range of diseases has been known for many years and the link between this phenomenon and the various pathologies has been the subject of much debate (Caughey and Lansbury 2003; Haass and Selkoe 2007; Jack et al. 2018). For systemic amyloidosis, the accumulation of large quantities of fibrillar deposits in vital organs is likely to result in their inability to function normally. In the case of neurodegenerative diseases, however, the amyloid burden can be quite low, and does not always relate to the severity of the symptoms (Lue et al. 1999). There is now a great deal of evidence that the most highly pathogenic species associated with amyloid formation are not the fibrillar deposits themselves but the prefibrillar oligomeric species that are populated during the aggregation process (Lue et al. 1999; Bucciantini et al. 2002; Kayed et al. 2003; Tomic et al. 2009; Benilova et al. 2012). Indeed, cellular toxicity has been observed to arise from oligomeric species formed by the aggregation of proteins unconnected to any pathological condition as well as those known to be associated with specific misfolding diseases (Bucciantini et al. 2002; Chiti and Dobson 2017).

The fundamental origin of such toxicity is attributable to the fact that these oligomers are inherently misfolded and, therefore, are likely to interact inappropriately with many of the functional components of the highly complex and crowded environments with which the latter have coevolved; the high surface-to-volume ratios of these species relative to larger aggregates, and their greater ability to spread by diffusion or other means, are also likely to be important factors in promoting high levels of cellular damage (Stefani and Dobson 2003; Guo and Lee 2014; Herling et al. 2018). The evidence from mechanistic studies that a range of species is present in a dynamic network throughout the process of protein aggregation strongly suggests that there is no unique "toxic agent" but that many misfolded species have the potential to generate at least some degree of toxicity. Indeed, it is clear that oligomeric intermediates can differ very significantly in their properties and their ability to induce given types of cellular dysfunction (Campioni et al. 2010; Cremades et al. 2012).

Although much remains to be learned about their nature and properties, it seems probable that the oligomers formed initially during the aggregation process of cytosolic proteins, at least, are relatively disordered species whose characteristics are likely to be strongly influenced by the sequestration from the aqueous environment of hydrophobic residues. In some cases, at least, it then appears that one or more conformational changes occurs to generate less disordered species with a significant content of $\beta$-sheet structure and a more highly hydrophobic surface that has greater potential to interact with cellular components such as membranes (Campioni et al. 2010; Cremades et al. 2012; Fusco et al. 2017). As such species increase in size, and ultimately form mature fibrils and plaques, many such hydrophobic regions are likely to become buried, reducing their potential to generate pathological effects; in addition, the increasing content of highly ordered structure progressively reduces their susceptibility to proteolysis and other degradation mechanisms, resulting in their increasing ability to accumulate in organs and tissue.

The ability of oligomeric species to disrupt cellular membranes is increasingly evident from experiments with lipid bilayers, where aggregates known to be cytotoxic have been shown 
C.M. Dobson et al.

to be able to insert into the bilayers (Fig. 4) and allow the ingress of $\mathrm{Ca}^{2+}$ ions, events that are then coupled to increases in reactive oxidative species (ROS) and ultimately cell death (Emak and Davies 2002; Stefani and Dobson 2003; Fusco et al. 2017). There is also evidence that the differences in the toxicity of oligomeric species can be related to specific structural characteristics; studies of stabilized oligomers of $\alpha$-synuclein have, for example, revealed the importance of the exposure of the amino-terminal region of the protein in such species for insertion into lipid bilayers (Fusco et al. 2017). It is also clear, however, that interactions of aggregates with specific receptors are also associated with the induction of cellular damage, and there is increasing recognition of the role of the inflammatory response in neurodegenerative diseases (Amor et al. 2010; Benilova et al. 2012).

The observation that many proteins can be thermodynamically unstable with respect to aggregation even under physiological conditions has been discussed above. Additional studies have provided yet further insight into this issue, as they have revealed that proteins appear generally to be present at concentrations that are at, or are close to, their solubility limits within the crowded cellular environments with which they have coevolved (Tartaglia et al. 2007). Such a situation reflects the balance between the need for proteins to remain soluble to perform their

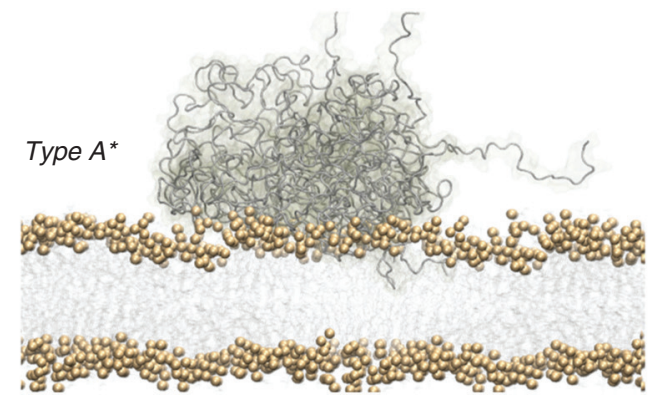

normal functions and the fact that random mutations tend to reduce protein solubility; the result is that even small changes, induced for example by mutations, posttranslational modifications or changes of concentration, can generate an increased risk of aggregation. Moreover, it has also emerged that some proteins are "supersaturated," in that they are present at levels in which they are highly metastable. It is particularly interesting that many of these proteins are found in pathways that are associated with neurodegenerative conditions, making them particularly vulnerable to aberrant behavior (Ciryam et al. 2015).

\section{AMYLOID FORMATION IN THE CONTEXT OF PROTEIN HOMEOSTASIS}

We now know that the inherent risks of protein aggregation, and of their likely deleterious consequences, are countered by the existence of an array of mechanisms with the ability of maintaining protein homeostasis (Fig. 1). In the context of amyloid formation, as well as the overall regulation of protein concentrations, molecular chaperones play key roles in targeting misfolded and aggregation-prone species either to induce correct refolding or to target them for degradation. Indeed, pathogenic behavior occurs when the quantities of misfolded and aggregationprone species reach levels in which the range of

Figure 4. The interaction of different types of stabilized oligomers of $\alpha$-synuclein with a lipid bilayer. Schematic representations of the binding of type $\mathrm{A}^{*}$ (largely disordered) (left) and type B* (having both ordered [red] and disordered [gray] regions) (right) oligomers to a lipid bilayer. The amino-terminal regions of the type $\mathrm{B}^{*}$ oligomers fold into amphipathic $\alpha$-helices (blue) upon interaction with the bilayer, and the ordered regions, which are rich in $\beta$-sheet structure insert into the bilayer and disrupt its integrity. (From Fusco et al. 2017; reprinted, with permission, from the American Association for the Advancement of Science @ 2017. ) 
regulatory mechanisms is unable to maintain protein solubility and homeostasis (Morimoto 2008; Douglas and Dillin 2010; Labbadia and Morimoto 2015). In the light of the key role that oligomeric aggregates appear to play in neurodegenerative conditions, much effort has been expended in exploring the way that the presence of such species is minimized, particularly under conditions of aging when the challenges in maintaining homeostasis increase (Morimoto 2008; Douglas and Dillin 2010; Labbadia and Morimoto 2015). Under such conditions, the initiation of the aggregation of even one particularly vulnerable protein may lead to a range of downstream processes involving many other proteins that then contribute substantially to the onset of disease.

Molecular chaperones have been shown in multiple studies to inhibit protein aggregation in vitro, and a wide range of biophysical studies have directly shown the interaction of molecular chaperones with oligomeric species. As an example, single-molecule fluorescence techniques have revealed the interaction of clusterin with the ensemble of oligomers observed during the aggregation of the A $\beta$-peptide (Narayan et al. 2011). Molecular chaperones have also been shown to reduce the toxicity associated with aggregation reactions both in cellular systems and in model organisms (Morimoto 2008; Hartl et al. 2011). In addition to their effects on the aggregation reactions themselves, in studies with stabilized and purified oligomeric species, the reduction of toxicity has been attributable to a variety of effects associated with the interactions of molecular chaperones with such species, including the inhibition of the binding of oligomers to cell membranes and the promotion of the further aggregation of the oligomers into larger and less damaging species (Mannini et al. 2012; Fusco et al. 2017).

Of particular interest are recent conclusions that have arisen from the extension of the methods of kinetic analysis discussed above in the context of the microscopic steps in the overall aggregation reaction. These studies have revealed that molecular chaperones have the ability to inhibit with remarkable efficacy very specific steps in the mechanisms that result in amyloid formation. One important example of this behavior has been the demonstration that the chaperone Brichos can inhibit extremely selectively the secondary nucleation processes associated with the aggregation of the $A \beta$-peptide (Fig. 5; Cohen et al. 2015). This inhibition has been shown to be associated with the binding of the molecular chaperone to the surfaces of the fibrils, thereby suppressing their ability to catalyze secondary nucleation processes. Such suppression is predicted from the kinetic analysis to reduce very significantly the population of oligomers, and indeed experiments confirm that the aggregation of the $A \beta$-peptide generates a much lower level of toxicity in the presence of Brichos (Cohen et al. 2015).

Additional studies reveal that other molecular chaperones are able to inhibit different steps in the aggregation process of the $A \beta$-peptides, and indeed of other proteins (Arosio et al. 2016). These observations suggest that the abundance of different molecular chaperones present within living organisms, and that are up-regulated in response to cellular stress, act in concert to inhibit the multitude of different aggregation pathways within the dynamic networks of intermediate species that are associated with the conversion of soluble proteins into amyloid fibrils.

More generally, increasing evidence indicates that certain cell and tissue types are more vulnerable than others to the effects of protein misfolding because of specific differences in the wide range of components of the protein homeostasis system responsible for the regulation of protein aggregation, including in particular trafficking and degradation pathways. Such cells and tissues are characterized by different transcriptional and proteomic signatures associated with the maintenance of aggregation-prone proteins, which are typically present for functional requirements, such as synaptic transmission and oxidative phosphorylation (Ciryam et al. 2016, 2017; Freer et al. 2016; Kundra et al. 2017; Fu et al. 2019). Further studies in this direction will increase our system-level understanding of misfolding disorders, and may provide new targets for therapeutic interventions as well as biomarkers for developing innovative diagnostic approaches. 
C.M. Dobson et al.
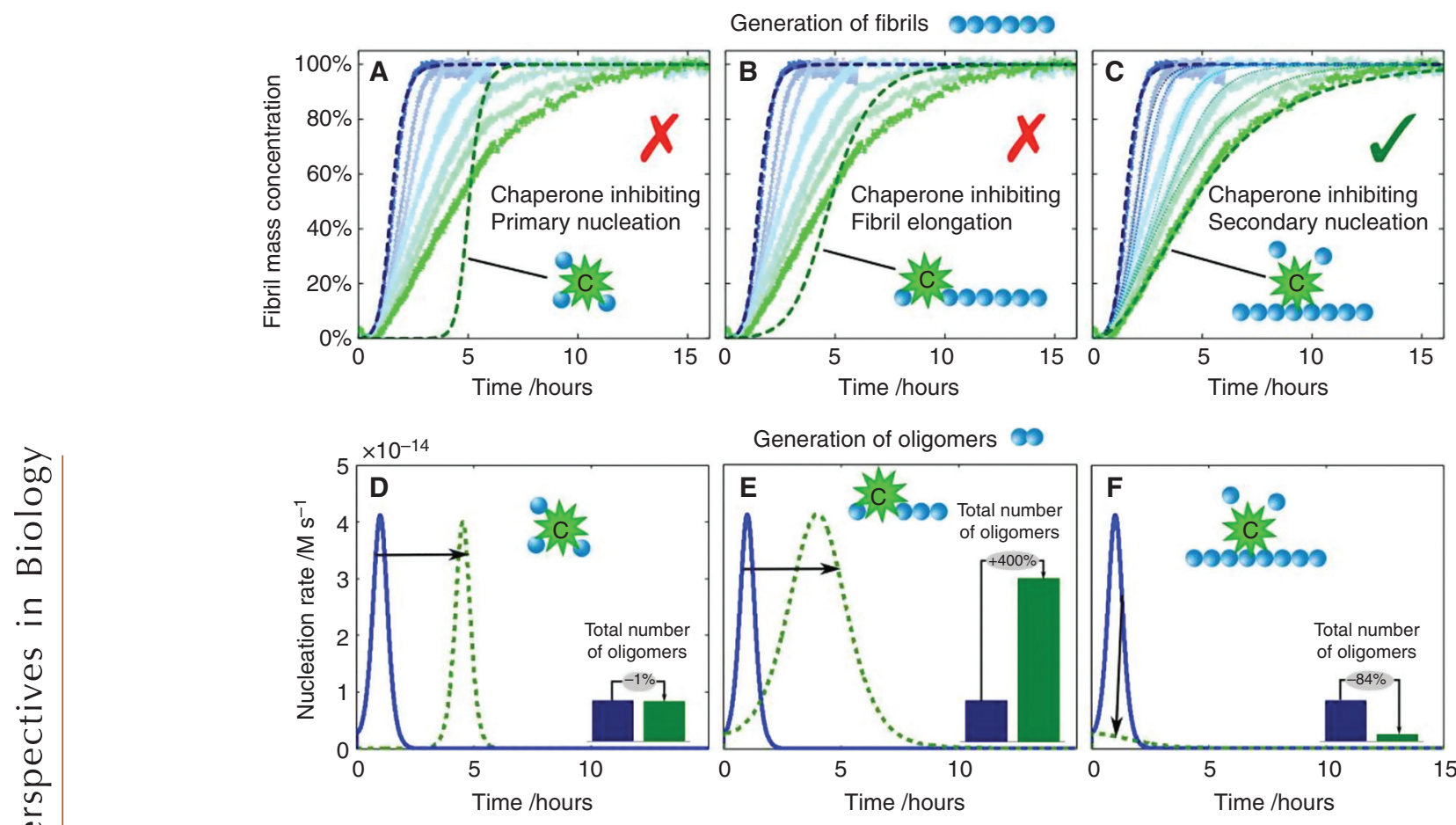

Generation of oligomers

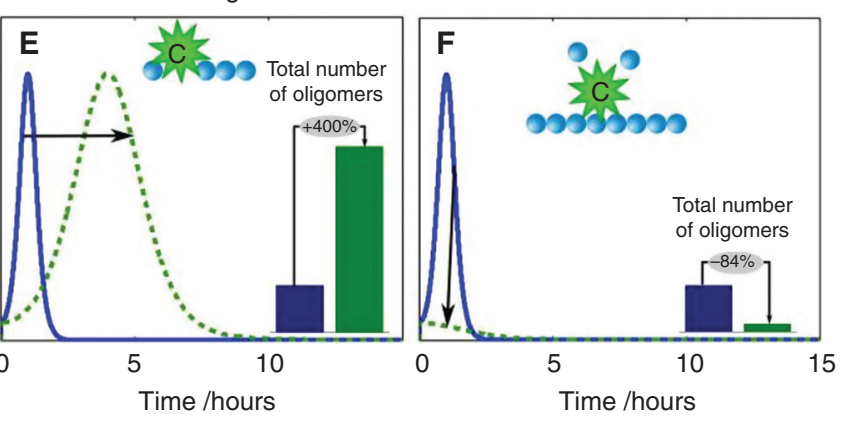

Figure 5. Kinetics of the 42 residue $A \beta$-peptide $(\mathrm{A} \beta 42)$ aggregation in the presence of the molecular chaperone Brichos. $(A-C)$ Reaction profiles from left (blue) to right (green) in the absence of Brichos and in the presence of increasing concentrations of Brichos up to a 1:1 stoichiometry. The blue dashed line is the integrated rate law for A 442 aggregation in the absence of Brichos using the rate constants determined previously. The green dashed lines show predictions of the resulting reaction profiles when each of $(A)$ primary nucleation, $(B)$ fibril elongation, and $(C)$ secondary (surface-catalyzed) nucleation is inhibited by the chaperone. The thin dotted lines in $(C)$ are theoretical predictions for the reaction profiles at the intermediate Brichos concentrations using the association and dissociation rate constants determined for its binding by means of surface plasmon resonance (SPR) measurements. $(D-F)$ Time evolution of the nucleation rates calculated from the kinetic analysis. The blue line corresponds to the situation in the absence of Brichos and the green dashed lines show predictions for the cases when each of $(D)$ primary nucleation, $(E)$ fibril elongation, and $(F)$ secondary nucleation is inhibited by the chaperone. The insets show the relative numbers of oligomers predicted to be generated during the aggregation reaction. (From Cohen et al. 2015; reprinted, with permission, from Nature Publishing Group () 2015 courtesy of the Open Access Licensing Policy.)

\section{STRATEGIES FOR THERAPEUTIC INTERVENTION}

Therapeutic strategies for long-established diseases, such as bacterial and viral infections, cancer, and heart conditions, involve such processes as the prevention of infection by external agents and the selective targeting of specific biochemical pathways associated with disease. These strategies, which have been developed over decades or even centuries of study, have proved to be increasingly effective in reducing the inci- dence of disease and also in limiting their effects on the individuals concerned. It is largely the advances in the prevention and treatment of these conditions that have resulted in the dramatic increase in human life span in recent years, and hence to the increasing prevalence of age-related amyloid disorders, particularly neurodegenerative conditions such as Alzheimer's disease. Such conditions, however, require different therapeutic approaches as they result fundamentally from the failure of control and regulatory processes that normally prevent 
our essential functional protein molecules converting into aberrant species with the potential to disrupt the normal processes on which living systems depend.

This rapid increase in the incidence of amyloid-related diseases has been such that until recently little detailed research had been performed to explore their molecular origins and means of progression. Early drug discovery efforts, at least partly for this reason, have led to very disappointing clinical trials, in particular those targeted at neurodegenerative conditions (Cummings et al. 2014, 2018). The progress in understanding the fundamental principles underlying misfolding and aggregation that has been made in recent years, however, now provides new opportunities to engage in rational therapeutic strategies (Fig. 6; Dobson 2004; Balch et al. 2008; Ong and Kelly 2011). In the following section of this review, this topic will be discussed in the context of the underlying molecular events associated with the aggregation process that have been discussed above, and of means of enhancing the ability of the natural protective mechanisms within living systems.

A major objective of any approach to the maintenance of human health is to try to prevent the onset of disease or to make its effects less deleterious. In the context of misfolding disorders, the initiation of the aggregation process can be followed by the rapid proliferation of aggregated proteins, making its suppression a particularly attractive therapeutic target. A pioneering demonstration of this approach is that designed for the treatment of amyloid-related conditions based on the aggregation of transthyretin (Johnson et al. 2005; Ong and Kelly 2011). This protein, whose function is to transport the thyroid hormone thyroxin, is tetrameric in its native state, but certain mutations result in its destabilization into monomers that are highly aggregation prone and give rise to both systemic and neurological conditions (Table 1). The native state of the protein can, however, be stabilized by binding to a substrate analog, hence reducing the risk of aggregation (Johnson et al.

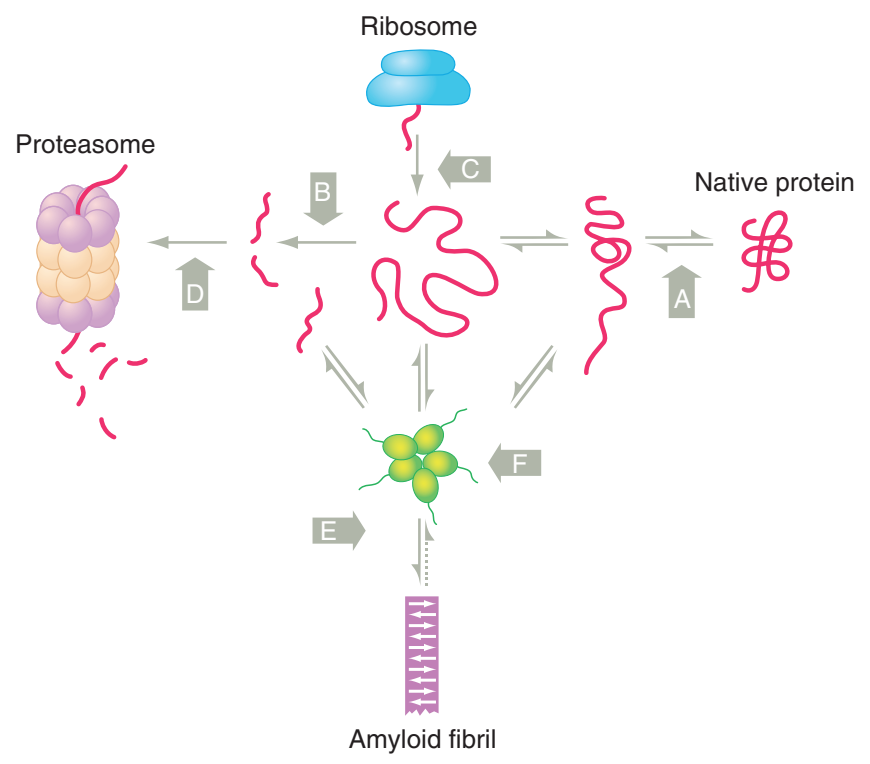

Figure 6. Schematic diagram indicating some of the processes following protein synthesis that can potentially be perturbed for therapeutic purposes to combat amyloid disorders. The various possible strategies include $(A)$ stabilizing the native state; $(B)$ inhibiting enzymes that process proteins into peptides with a higher propensity to aggregate; $(C)$ inhibiting protein synthesis; $(D)$ stimulating clearance of misfolded proteins, for example, by boosting proteasomal degradation; $(E)$ perturbing the assembly of fibrils; and $(F)$ suppressing the formation of toxic oligomeric fibril precursors. (Image based on data in Ciryam et al. 2017.) 
2005). This strategy has been used very effectively to develop a drug, tafamidis, which is currently in clinical use to treat familial amyloid polyneuropathy (Said et al. 2012).

Stabilizing the native state, however, is problematic for the proteins whose aggregation is associated with most neurological conditions, including Alzheimer's and Parkinson's diseases, which are natively disordered and therefore lack specific tight binding sites for other molecules (Dyson and Wright 2005; Heller et al. 2018). An alternative strategy to suppress aggregation is therefore to inhibit one or more of the microscopic steps involved in the process of amyloid formation, thereby reducing the risk in particular of the accumulation of toxic oligomeric intermediates, in an analogous way to that observed to result from the presence of molecular chaperones. Recent studies of the $A \beta$-peptides and $\alpha$-synuclein have resulted in the identification of a range of small molecules that are highly effective in vitro in reducing the rates of primary or secondary nucleation, or indeed both; such molecules have also been found to be effective in reducing very substantially the generation of amyloid deposits in vivo using Caenorhabditis elegans as a model system (Fig. 7; Habchi et al. 2016; Perni et al. 2017). With the development of high-throughput screening methods, it has been shown that the efficacy of such inhibitors can be increased very significantly by methods analogous to those used in conventional drug discovery techniques, except that they use the measurement of kinetic parameters rather than binding affinities (Chia et al. 2018).

Some of the molecules that are emerging from such studies are natural products of drugs already approved for other conditions, making repurposing a very real possibility. In addition to small molecules, antibodies are being widely explored in the context of potential therapeutic strategies to combat neurodegenerative conditions (Schenck 2002; Sevigny et al. 2016), and recent work has revealed their ability to inhibit individual steps in the aggregation of specific proteins. A series of single-domain antibodies has been designed by computational methods to bind to short stretches along the sequence of the $A \beta$-peptide; these molecules have been found to inhibit the microscopic steps in the aggregation process in distinctive ways, affecting primary and secondary nucleation to different extents (Fig. 8; Aprile et al. 2017). Taken together, these results suggest that it should be possible to reduce the level of toxic oligomeric species, by means of small molecules or macromolecules, to levels that enable the protective cellular mechanisms to maintain protein homeostasis for longer periods of time and hence postpone into older ages the onset of disease.

\section{LOOKING TO THE FUTURE}

Our knowledge of the fundamental nature and significance of the amyloid states of proteins has developed very rapidly in recent years, enabling us to understand at a molecular level many aspects of their structures and properties, the mechanisms by which they can be formed from the functional states of proteins, and the manner in which such mechanisms are controlled and regulated in healthy living systems. As a result, it is becoming possible to gain new insights into the way that the properties of functional proteins have coevolved with their environments to enable protein homeostasis to be maintained under normal physiological conditions, but to be vulnerable to impairment under others, for example, as a consequence of mutations or of aging. Such insights also suggest opportunities to intervene therapeutically to reduce the risk of the initiation of aggregation, an approach that should be preventative against the onset of disease, or to reduce the generation of toxic oligomeric species during the course of aggregation, a process that should represent a potential means of treatment. In both situations, a key objective is to enhance by such means the natural protective mechanisms within cells and tissues to enable protein homeostasis to be maintained, particularly into older age.

Although a great deal has now been established about the physical nature of the amyloid phenomenon and its relationship to biology and medicine, there remains much to be done. Thus, for example, we need to determine in greater detail the structural characteristics of the oligomeric states that are an inherent feature of the process 

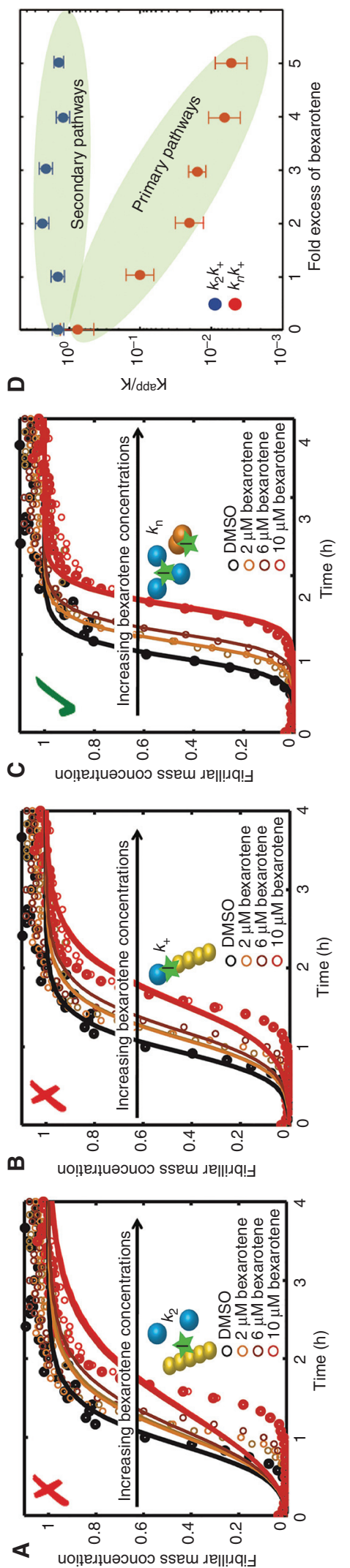

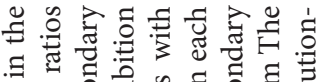

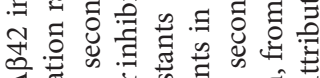

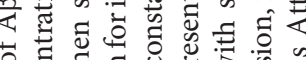

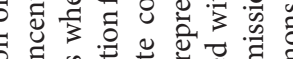

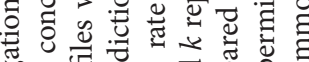
.0.

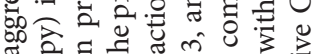

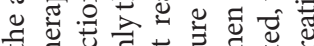

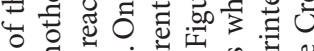
\&

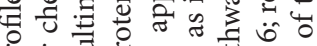

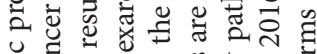

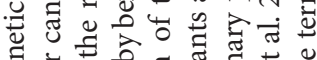

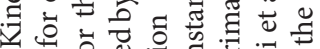

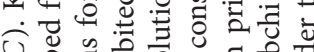

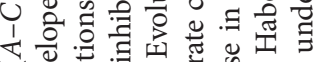

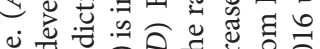

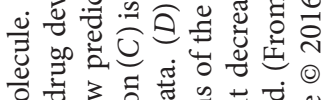
घ 击

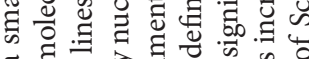
$\pi$

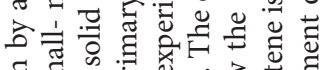

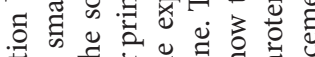

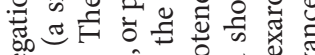

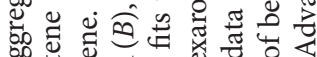
(⿻)

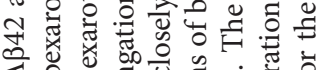

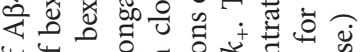

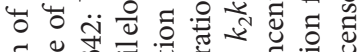

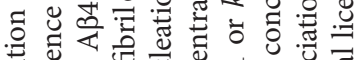

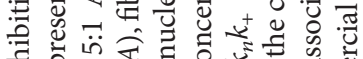

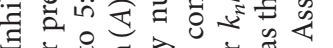

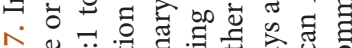

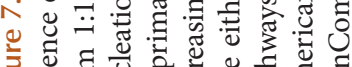

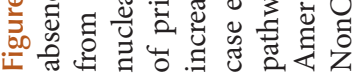


C.M. Dobson et al.

A

A
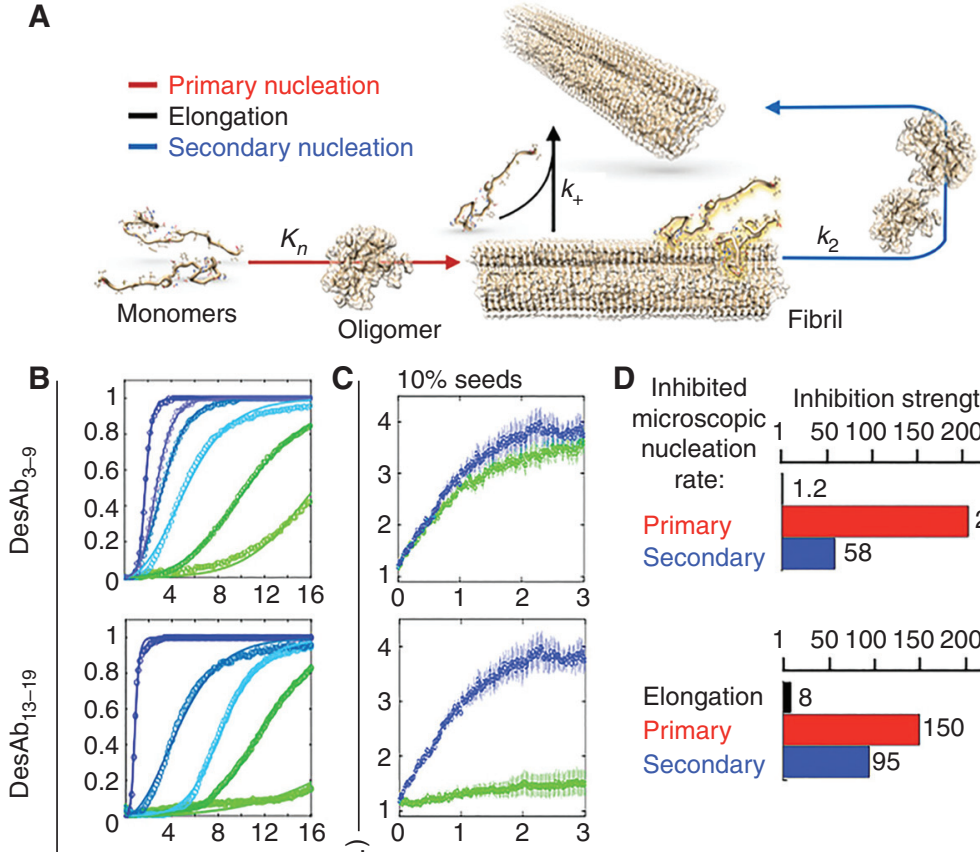

D Inhibited
microscopic $_{1} \quad$ Inhibition strength
50100150200250

E Total

nucleation oligomers

rate:

Primary

Secondary

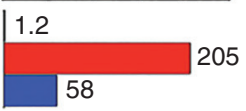

$-90 \%$

(1)
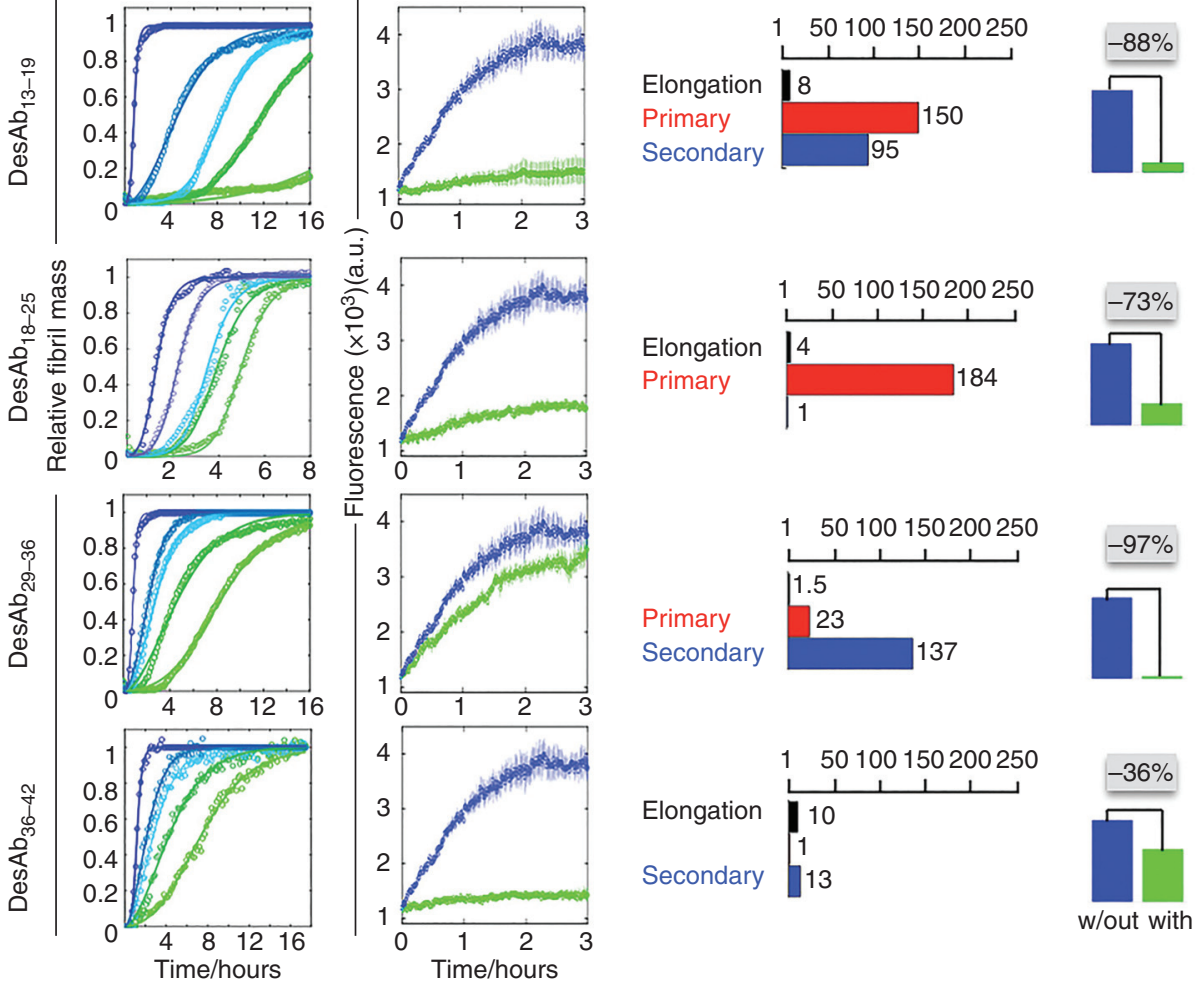

Figure 8. The antibody scanning method produces antibodies that affect different microscopic steps in the aggregation of $\mathrm{A} \beta 42$. (A) Schematic of $\mathrm{A} \beta 42$ aggregation showing the primary (red arrow) and secondary (blue arrow) nucleation of the aggregation process and the elongation of fibrils (black). (B) The designed antibodies (DesAbs) were generated to target five different epitopes in the A $\beta 42$ sequence (indicated on the left side) and the kinetics of aggregation were monitored at different concentrations of each DesAb at increasing (blue to green) concentrations relative to that of A 342 . (C) Seeded aggregation at a low (blue) or high (green) concentration of added fibrils. $(D)$ Bar plots showing that each DesAb inhibits the microscopic steps in the aggregation process in a different way; the fold change of each of the rate constants is shown at the top of the corresponding bar. (E) The relative number of oligomers generated during the aggregation reaction with 1:2 DesAb:A $\beta 42$ ratios. (From Aprile et al. 2017; reprinted, with permission, from the American Association for the Advancement of Science (C) 2016 under the terms of the Creative Commons Attribution-NonCommercial license.) 
of protein aggregation, to define more fully the dynamic network of events involved in their interconversion, and to understand in greater depth the nature and consequences of their interactions with living systems. We need also to know more about the mechanisms by which homeostasis is preserved, and the manner in which it becomes impaired during the process of aging. In the context of human health, particularly for neurodegenerative conditions, we need enhanced diagnostic methods and improved biomarkers through which to monitor the effects of potential drugs more quantitatively, and at earlier stages of disease, than is currently possible. The increasing recognition of the impact of these conditions, and the greater interactions that are now developing in this area between the physical, biological, and medical sciences, suggest that we should be optimistic about rapid progress in this vital field of human health and welfare.

Finally, it is hard to overestimate the need for enhanced levels of research to generate rapid progress. A large fraction of the human race is now suffering from highly debilitating and incurable amyloid-related conditions that already place huge burdens on the financial resources and health care systems of the world (World Alzheimer Report 2018). The increase in longevity achieved in recent decades has already resulted in neurodegenerative conditions becoming the leading cause of death in many parts of the world, and suggests that the numbers of people afflicted by such disorders alone will more than double in the next 25 years, the majority of whom will be in low and middle-income countries (World Alzheimer Report 2018). The study of the nature of protein misfolding and aggregation, and its contribution to loss of protein homeostasis in aging, promises to be the crucial step in the development of the means to address one of the greatest challenges facing humanity in the modern age.

\section{ACKNOWLEDGMENTS}

We acknowledge the major contributions to the work described in this article of the many graduate students, postdoctoral fellows, colleagues, and other collaborators whose discoveries and ideas are reflected in its content, many of whose names appear in the citations to published work. This article is an extensively revised and updated version of material discussed in Knowles et al. (2014) and Dobson (2013). We also express our gratitude to the many organizations that have funded our research over many years, including the Wellcome Trust, the Leverhulme Trust, the Royal Society, Alzheimer's Research UK, Parkinson's UK, the European Commission, the UK Research Councils, and the Cambridge Centre for Misfolding Diseases.

\section{REFERENCES}

Aguzzi A, Calella AM. 2009. Prions: Protein aggregation and infectious diseases. Physiol Rev 89: 1105-1152. doi:10 .1152 /physrev.00006.2009

Amor S, Puentas F, Baker D, van der Valk P. 2010. Inflammation in neurodegenerative diseases. Immunology 129: 154-169. doi:10.1111/j.1365-2567.2009.03225.x

Aprile FA, Sormanni P, Perni M, Arosio P, Linse S, Knowles TPJ, Dobson CM, Vendruscolo M. 2017. Selective targeting of primary and secondary nucleation pathways in A 342 aggregation using a rational antibody scanning method. Sci Adv 3: e1700488. doi:10.1126/sciadv 1700488 .

Arosio P, Michaels TCT, Linse S, Månsson C, Emanuelsson C, Presto J, Johansson J, Vendruscolo M, Dobson CM, Knowles TPJ. 2016. Kinetic analysis reveals the diversity of microscopic mechanisms through which molecular chaperones suppress amyloid formation. Nat Commun 7: 10948. doi: $10.1038 /$ ncomms 10948

Balch WE, Morimoto RI, Dillin A, Kelly JW. 2008. Adapting proteostasis for disease intervention. Science 319: 916919. doi:10.1126/science.1141448

Baldwin AJ, Knowles TPJ, Tartaglia GG, Fitzpatrick AW, Devlin GL, Shammas SL, Waudby CA, Mossuto MF, Meehan S, Gras SL, et al. 2011. Metastability of native proteins and the phenomenon of amyloid formation. $J$ Am Chem Soc 133: 14160-14163. doi:10.1021/ja2017703

Benilova I, Karran E, De Stroopoer B. 2012. The toxic A $\beta$ oligomer and Alzheimer's disease: An emperor in need of clothes. Nat Neurosci 15: 349-357. doi:10.1038/nn.3028

Broome BM, Hecht MH. 2000. Nature disfavours sequences of alternative polar and non-polar amino acids: Implications for amyloidogenesis. J Mol Biol 296: 961-968. doi:10 .1006/jmbi.2000.3514

Bucciantini M, Giannoni E, Chiti F, Baroni F, Formigli L, Zurdo J, Taddei N, Ramponi G, Dobson CM, Stefani M. 2002. Inherent toxicity of aggregates implies a common mechanism for protein misfolding diseases. Nature 416: 507-511. doi:10.1038/416507a

Campioni S, Mannini B, Zampagni M, Pensalfini A, Parrini C, Evangelisti E, Relini A, Stefani M, Dobson CM, Cecchi C, et al. 2010. A causative link between the structure of aberrant protein oligomers and their toxicity. Nat Chem Biol 6: 140-147. doi:10.1038/nchembio.283 
C.M. Dobson et al.

Caughey B, Lansbury PT. 2003. Protofibrils, pores, fibrils, and neurodegeneration: Separating the responsible protein aggregates from the innocent bystanders. Annu Rev Neurosci 26: 267-298. doi:10.1146/annurev.neuro.26 .010302 .081142

Chia S, Habchi J, Michaels TCT, Cohen SIA, Linse S, Dobson CM, Knowles TPJ, Vendruscolo M. 2018. SAR by kinetics for drug discovery in protein misfolding diseases. Proc Natl Acad Sci 115: 10245-10250. doi:10.1073/pnas 1807884115

Chiti F, Dobson CM. 2017. Protein misfolding, amyloid formation, and human disease: A summary of progress over the last decade. Ann Rev Biochem 86: 27-68. doi:10.1146/ annurev-biochem-061516-045115

Ciryam P, Kundra R, Morimoto RI, Dobson CM, Vendruscolo M. 2015. Supersaturation is a major driving force for protein aggregation in neurodegenerative diseases. Trends Pharmacol Sci 36: 72-77. doi:10.1016/j.tips.2014.12.004

Ciryam P, Kundra R, Freer R, Morimoto RI, Dobson CM, Vendruscolo M. 2016. A transcriptional signature of Alzheimer's disease is associated with a metastable subproteome at risk of aggregation. Proc Natl Acad Sci 113. 4753-4758. doi:10.1073/pnas.1516604113

Ciryam P, Lambert-Smity IA, Bean DM, Freer R, Cid F, Tartaglia GG, Saunders DN, Wilson MR, Oliver SG, Morimoto RI, et al. 2017. Spinal motor neuron protein supersaturation patterns are associated with inclusion body formation in ALS. Proc Natl Acad Sci 114: E3935E3943. doi:10.1073/pnas.1613854114

Cohen SIA, Linse S, Luheshi LM, Hellstrand E, White DA, Rajah L, Otzen DE, Vendruscolo $M$, Dobson CM, Knowles TPJ. 2013. Proliferation of amyloid- $\beta 42$ aggregates occurs through a secondary nucleation mechanism. Proc Natl Acad Sci 110: 9758-9763. doi:10.1073/pnas 1218402110

Cohen SIA, Arosio P, Presto J, Kurudenkandy FR, Biverstål H, Dolfe L, Dunning C, Yang X, Frohm B, Vendruscolo $\mathrm{M}$, et al. 2015. A molecular chaperone breaks the catalytic cycle that generates toxic A $\beta$ oligomers. Nat Struct Mol Biol 22: 207-213. doi:10.1038/nsmb.2971

Colvin MT, Silvers R, Frohm B, Su Y, Linse S, Griffin RG. 2015. High resolution structural characterization of $A \beta 42$ amyloid fibrils by magic angle spinning NMR. J Am Chem Soc 137: 7509-7518. doi:10.1021/jacs.5b03997

Cremades N, Cohen SIA, Deas E, Abramov AY, Chen AY, Orte A, Sandal M, Clarke RW, Dunne P, Aprile FA, et al. 2012. Direct observation of the interconversion of normal and toxic forms of $\alpha$-synuclein. Cell 149: 1048-1059. doi:10.1016/j.cell.2012.03.037

Cummings JL, Morstorf T, Zhong K. 2014. Alzheimer's disease drug-development pipeline: Few candidates, frequent failures. Alzheimers Res Ther 6: 37. doi:10.1186/ alzrt269

Cummings J, Lee G, Ritter A, Zhong K. 2018. Alzheimer's disease drug development pipeline: 2018. Alzheimers Dement 4: 195-214.

Dobson CM. 2003. Protein folding and misfolding. Nature 426: 884-890. doi:10.1038/nature02261

Dobson CM. 2004. In the footsteps of alchemists. Science 304: 1259-1262. doi:10.1126/science. 1093078

Dobson CM. 2013. The amyloid phenomenon and its significance. In Amyloid fibrils and prefibrillar aggregates:
Molecular and biological properties (ed. DE Otzen), pp. 1-19. Wiley, Hoboken, NJ.

Douglas PM, Dillin A. 2010. Protein homeostasis and aging in neurodegeneration. J Cell Biol 190: 719-729. doi:10 $1083 /$ jcb.201005144

Dyson HJ, Wright PE. 2005. Intrinsically unstructured proteins and their functions. Nat Rev Mol Cell Biol 6: 197208. doi: $10.1038 / \mathrm{nrm} 1589$

Eisenberg D, Jucker M. 2012. The amyloid state of proteins in human diseases. Cell 148: 1188-1203. doi:10.1016/j cell.2012.02.022

Emak G, Davies KJ. 2002. Calcium and oxidative stress: From cell signaling to cell death. Mol Immunol 38: 713721. doi:10.1016/S0161-5890(01)00108-0

Fändrich M, Dobson CM. 2002. The behaviour of polyamino acids reveals an inverse side chain effect in amyloid structure formation. EMBO J 21: 5682-5690. doi:10.1093/ emboj/cdf573

Fitzpatrick AWP, Falcon B, He S, Murzin AG, Murshudov G, Garringer HJ, Crowther RA, Ghetti B, Goedert M, Scheres SHW. 2017. Cryo-EM structures of tau filaments from Alzheimer's disease. Nature 547: 185-190. doi:10.1038/ nature 23002

Fowler DM, Koulov AV, Balch WE, Kelly JW. 2007. Functional amyloid-From bacteria to humans. Trends Biochem Sci 32: 217-224. doi:10.1016/j.tibs.2007.03.003

Freer R, Sormanni P, Vecchi G, Ciryam P, Dobson CM, Vendruscolo M. 2016. A protein homeostasis signature in healthy brains recapitulates tissue vulnerability to Alzheimer's disease. Sci Adv 2: e1600947. doi:10.1126/sciadv .1600947

Fu H, Possenti A, Freer R, Nakano Y, Vallegas NCH, Tang M, Cauhy PVM, Lassus BA, Chen S, Fowler SL, et al. 2019. A tau homeostasis signature is linked with the cellular and regional vulnerability of excitatory neurons to tau pathology. Nat Neurosci 22: 47-56. doi:10.1038/s41593-0180298-7

Fusco G, Chen SW, Williamson PTF, Cascella R, Perni M, Jarvis JA, Cecchi C, Vendruscolo M, Chiti F, Cremades N, et al. 2017. Structural basis of membrane disruption and cellular toxicity by $\alpha$-synuclein oligomers. Science 358: 1440-1443. doi:10.1126/science.aan6160

Galvagnion C, Buell AK, Meisl G, Michaels TCT, Vendruscolo M, Knowles TPJ, Dobson CM. 2015. Lipid vesicles trigger $\alpha$-synuclein aggregation by stimulating primary nucleation. Nat Chem Biol 11: 229-234. doi:10.1038/ nchembio. 1750

Gazit E. 2002. The "correctly folded" state of proteins: Is it a metastable state? Angew Chem Int Ed Engl 41: 257-259. doi:10.1002/1521-3773(20020118)41:2<257::AIDANIE257>3.0.CO;2-M

Guo JL, Lee VM. 2014. Cell-to-cell transmission of pathogenic proteins in neurodegenerative diseases. Nat Med 20: 130-138. doi:10.1038/nm.3457

Haass C, Selkoe DJ. 2007. Soluble protein oligomers in neurodegeneration: Lessons from the Alzheimer's amyloid $\beta$ peptide. Nat Rev Mol Cell Biol 8: 101-112. doi:10.1038/ nrm2101

Habchi J, Arosio P, Perni M, Costa AR, Yagi-Utsumi M, Joshi P, Chia S, Cohen SIA, Müller MBD, Linse S, et al. 2016. An anticancer drug suppresses the primary 
nucleation reaction that initiates the production of the toxic A $\beta 42$ aggregates linked with Alzheimer's disease. Sci Adv 2: e1501244. doi:10.1126/sciadv.1501244

Hartl FU, Bracher A, Hayer-Hartl M. 2011. Molecular chaperones in protein folding and proteostasis. Nature 475: 324-332. doi:10.1038/nature10317

Heller GT, Bonomi M, Vendruscolo M. 2018. Structural ensemble modulation upon small-molecule binding to disordered proteins. J Mol Biol 430: 2288-2292. doi:10 $.1016 /$ j.jmb.2018.03.015

Herling TW, Levin A, Saar KL, Dobson CM, Knowles TPJ. 2018. Microfluidic approaches for probing amyloid formation and behaviour. Lab Chip 18: 999-1016. doi:10 $.1039 / \mathrm{C} 7 \mathrm{LC} 01241 \mathrm{~A}$

Jack CR Jr., Bennett DA, Blennow K, Carrillo MC, Dunn B, Haeberlein SB, Holtzman DM, Jagust W, Jessen F, Karlawish J, et al. 2018. NIA-AA research framework: Toward a biological definition of Alzheimer's disease. Alzheimers Dement 14: 535-562. doi:10.1016/j.jalz.2018.02.018.

Jiménez JL, Nettleton EJ, Bouchard M, Robinson CV, Dobson CM, Saibil HR. 2002. The protofilament structure of insulin amyloid fibrils. Proc Natl Acad Sci 99: 9196-9201. doi:10.1073/pnas.142459399

Johnson SM, Wiseman RL, Sekijima Y, Green NS, AdamskiWerner SL, Kelly JW. 2005. Native state kinetic stabilization as a strategy to ameliorate protein misfolding diseases: A focus on the transthyretin amyloidoses. Acc Chem Res 38: 911-921. doi:10.1021/ar020073i

Kaminski Schierle GS, van de Linde S, Erdelyi M, Esbjörner EK, Klein T, Rees E, Bertoncini CW, Dobson CM, Sauer M, Kaminski CF. 2011. In situ measurements of the formation and morphology of intracellular $\beta$-amyloid fibrils by super-resolution fluorescence imaging. J Am Chem Soc 133: 12902-12905. doi:10.1021/ja201651w

Kayed R, Head E, Thompson JL, McIntire TM, Milton SC, Cotman CW, Glabe CG. 2003. Common structure of soluble amyloid oligomers implies common mechanism of pathogenesis. Science 300: 486-489. doi:10.1126/sci ence.1079469

Knowles TPJ, Buehler MJ. 2011. Nanomechanics of functional and pathological amyloid materials. Nat Nanotechnol 6: 469-479. doi:10.1038/nnano.2011.102

Knowles TPJ, Fitzpatrick AW, Meehan S, Mott HR, Vendruscolo M, Dobson CM, Welland ME. 2007. Role of intermolecular forces in defining material properties of protein nanofibrils. Science 318: 1900-1903. doi:10.1126/ science. 1150057

Knowles TPJ, Waudby CA, Devlin GL, Cohen SIA, Aguzzi A, Vendruscolo M, Terentjev EM, Welland ME, Dobson CM. 2009. An analytical solution to the kinetics of breakable filament assembly. Science 326: 1533-1537. doi:10 $.1126 /$ science. 1178250

Knowles TPJ, White DA, Abate AR, Agresti JJ, Cohen SIA, Sperling RA, De Genst EJ, Dobson CM, Weitz DA. 2011. Observation of spatial propagation of amyloid assembly from single nuclei. Proc Natl Acad Sci 108: 14746-14751. doi:10.1073/pnas.1105555108

Knowles TPJ, Vendruscolo M, Dobson CM. 2014. The amyloid state and its association with protein misfolding diseases. Nat Rev Mol Cell Biol 15: 384-396. doi:10 $.1038 / \mathrm{nrm} 3810$
Amyloid Phenomenon in Biology and Medicine

Kundel F, Hong L, Falcon B, McEwan WA, Michaels TCT, Meisl G, Esteras N, Abramov AY, Knowles TPJ, Goedert $\mathrm{M}$, et al. 2018. Measurement of tau filament fragmentation provides insights into prion-like spreading. ACS Chem Neurosci 9: 1276-1282. doi:10.1021/acschem neuro.8b00094

Kundra R, Ciryam P, Morimoto RI, Dobson CM, Vendruscolo M. 2017. Protein homeostasis of a metastable subproteome associated with Alzheimer's disease. Proc Natl Acad Sci 114: E5703-E5711. doi:10.1073/pnas .1618417114

Labbadia J, Morimoto RI. 2015. The biology of proteostasis in aging and disease. Annu Rev Biochem 84: 435-464. doi:10.1146/annurev-biochem-060614-033955

Lue LF, Kuo YM, Roher AE, Brachova L, Shen Y, Sue L, Beach T, Kurth JH, Rydel RE, Rogers J. 1999. Soluble amyloid $\beta$ peptide concentration as a predictor of synaptic change in Alzheimer's disease. Am J Pathol 155: 853-862. doi:10.1016/S0002-9440(10)65184-X

Luheshi LM, Crowther DC, Dobson CM. 2008. Protein misfolding and disease: From the test tube to the organism. Curr Opin Chem Biol 12: 25-31. doi:10.1016/j.cbpa.2008 .02 .011

Maji SK, Perrin MH, Sawaya MR, Jessberger S, Vadodaria K, Rissman RA, Singru PS, Nilsson KP, Simon R, Schubert D, et al. 2009. Functional amyloids as natural storage of peptide hormones in pituitary secretory granules. Science 325: 328-332. doi:10.1126/science.1173155

Mannini B, Cascella R, Zampagni M, van Waarde-Verhagen M, Meehan S, Roodveldt C, Campioni S, Boninsegna M Penco A, Relini A, et al. 2012. Molecular mechanisms used by chaperones to reduce the toxicity of aberrant protein oligomers. Proc Natl Acad Sci 109: 1247912484. doi:10.1073/pnas.1117799109

Meisl G, Kirkegaard JB, Arosio P, Michaels TCT, Vendruscolo M, Dobson CM, Linse S, Knowles TPJ. 2016. Molecular mechanisms of protein aggregation from global fitting of kinetic models. Nat Protoc 11: 252-272. doi:10 $.1038 /$ nprot.2016.010

Michaels TCT, Šarić A, Habchi J, Chia S, Meisl G, Vendruscolo M, Dobson CM, Knowles TPJ. 2018. Chemical kinetics for bridging molecular mechanisms and macroscopic measurements of amyloid fibril formation. Annu Rev Phys Chem 69: 273-298. doi:10.1146/annurev-phys chem-050317-021322

Morimoto RI. 2008. Proteotoxic stress and inducible chaperone networks in neurodegenerative disease and aging. Genes Dev 22: 1427-1438. doi:10.1101/gad.1657108

Narayan P, Orte A, Clarke RW, Bolognesi B, Hook S, Ganzinger KA, Meehan S, Wilson MR, Dobson CM, Klenerman D. 2011. The extracellular chaperone clusterin sequesters oligomeric forms of the amyloid- $\beta(1-40)$ peptide. Nat Struct Mol Biol 19: 79-83. doi:10.1038/ nsmb.2191

Nelson R, Sawaya MR, Balbirnie M, Madsden AØ, Riekel C, Grothe R, Eisenberg D. 2005. Structure of the cross- $\beta$ spine of amyloid-like fibrils. Nature 435: 773-778. doi: $10.1038 /$ nature 03680

Ong DS, Kelly JW. 2011. Chemical and/or biological therapeutic strategies to ameliorate protein misfolding diseases. Curr Opin Cell Biol 23: 231-238. doi:10.1016/j.ceb .2010 .11 .002 
C.M. Dobson et al.

Pawar AP, Dubay KF, Zurdo J, Chiti F, Vendruscolo M Dobson CM. 2005. Prediction of "aggregation-prone" and "aggregation-susceptible" regions in proteins associated with neurodegenerative diseases. J Mol Biol 350: 379-392. doi:10.1016/j.jmb.2005.04.016

Perni M, Galvagnion C, Maltsev A, Meisl G, Müller MB, Challa PK, Kirkegaard JB, Flagmeier P, Cohen SIA, Cascella R, et al. 2017. A natural product inhibits the initiation of $\alpha$-synuclein aggregation and suppresses its toxicity. Proc Natl Acad Sci 114: E1009-E1017. doi:10.1073/ pnas. 1610586114

Petkova AT, Ishii Y, Balbach JJ, Antzutkin ON, Leapman RD, Delaglio F, Tycko R. 2002. A structural model for Alzheimer's $\beta$-amyloid fibrils based on experimental constraints from solid state NMR. Proc Natl Acad Sci 99: 16742-16747. doi:10.1073/pnas.262663499

Petkova AT, Leapman RD, Guo Z, Yau WM, Mattson MP, Tycko R. 2005. Self-propagating, molecular-level polymorphism in Alzheimer's $\beta$-amyloid fibrils. Science 307: 262-265. doi:10.1126/science.1105850

Robinson CV, Sali A, Baumeister W. 2007. The molecular sociology of the cell. Nature 450: 973-982. doi:10.1038/ nature 06523

Sachse C, Fändrich M, Grigorieff N. 2008. Paired $\beta$-sheet structure of an $A \beta(1-40)$ amyloid fibril revealed by electron microscopy. Proc Natl Acad Sci 105: 7462-7466. doi:10.1073/pnas.0712290105

Safar J, Wille H, Itri V, Groth D, Serban H, Torchia M, Cohen FE, Prusiner SB. 1998. Eight prion strains have $\operatorname{PrP}(\mathrm{Sc})$ molecules with different conformations. Nat Med 4: 1157-1165. doi:10.1038/2654

Said G, Grippon S, Kirkpatrick P. 2012. Tafamidis. Nat Rev Drug Discov 11: 185-186. doi:10.1038/nrd3675.

Schenck D. 2002. Amyloid- $\beta$ immunotherapy for Alzheimer's disease: The end of the beginning. Nat Rev Neurosci 3: $824-828$. doi:10.1038/nrn938

Sevigny J, Chiao P, Bussière T, Weinreb PH, Williams L, Maier M, Dunstan R, Salloway S, Chen T, Ling Y, et al. 2016. The antibody aducanumab reduces $\mathrm{A} \beta$ plaques in Alzheimer's disease. Nature 537: 50-56. doi:10.1038/na ture19323.
Shimanovich U, Efimov I, Mason TO, Flagmeier P, Buell AK, Gedanken A, Linse S, Åkerfeldt KS, Dobson CM, Weitz DA, et al. 2015. Protein microgels from amyloid fibril networks. ACS Nano 9: 43-51. doi:10.1021/nn504869d

Stefani M, Dobson CM. 2003. Protein aggregation and aggregate toxicity: New insights into protein folding, misfolding diseases and biological evolution. J Mol Med 81: 678-699. doi:10.1007/s00109-003-0464-5

Sunde M, Serpell LC, Bartlam M, Fraser PE, Pepys MB, Blake CCF. 1997. Common core structure of amyloid fibrils by synchrotron X-ray diffraction. J Mol Biol 273: 729-739. doi:10.1006/jmbi.1997.1348

Tartaglia GG, Pechmann S, Dobson CM, Vendruscolo M. 2007. Life on the edge: A link between gene expression levels and aggregation rates of human proteins. Trends Biochem Sci 32: 204-206. doi:10.1016/j.tibs.2007.03.005

Tartaglia GG, Pawar AP, Campioni S, Dobson CM, Chiti F, Vendruscolo M. 2008. Prediction of aggregation-prone regions in structured proteins. J Mol Biol 380: 425-436. doi:10.1016/j.jmb.2008.05.013

Tomic JL, Pensalfini A, Head E, Glabe CG. 2009. Soluble fibrillar oligomer levels are elevated in Alzheimer's disease brain and correlate with cognitive dysfunction. $\mathrm{Neu}$ robiol Dis 35: 352-358. doi:10.1016/j.nbd.2009.05.024

Törnquist M, Michaels TCT, Sanagavarapu K, Yang X, Meisl G, Cohen SIA, Knowles TPJ, Linse S. 2018. Secondary nucleation in amyloid formation. Chem Commun 54: 8667-8684. doi:10.1039/C8CC02204F

Vendruscolo M, Knowles TPJ, Dobson CM. 2011. Protein solubility and protein homeostasis: A generic view of protein misfolding disorders. Cold Spring Harb Perspect Biol 3: a010454. doi:10.1101/cshperspect.a010454

Wei G, Su Z, Reynolds NP, Arosio P, Hamley IW, Gazit E, Mezzenga R. 2017. Self-assembling peptide and protein amyloids: From structure to tailored function in nanotechnology. Chem Soc Rev 46: 4661-4708. doi:10.1039/ C6CS00542J

World Alzheimer Report. 2018. Alzheimer's Disease International. www.alz.co.uk/worldreport2018. 


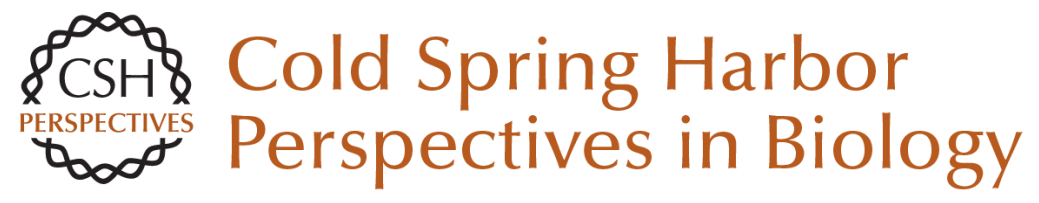

\section{The Amyloid Phenomenon and Its Significance in Biology and Medicine}

Christopher M. Dobson, Tuomas P.J. Knowles and Michele Vendruscolo

Cold Spring Harb Perspect Biol 2020; doi: 10.1101/cshperspect.a033878 originally published online April 1,2019

\section{Subject Collection Protein Homeostasis}

Proteome-Scale Mapping of Perturbed

Proteostasis in Living Cells

Isabel Lam, Erinc Hallacli and Vikram Khurana

Pharmacologic Approaches for Adapting Proteostasis in the Secretory Pathway to

Ameliorate Protein Conformational Diseases Jeffery W. Kelly

Cell-Nonautonomous Regulation of Proteostasis

in Aging and Disease

Richard I. Morimoto

The Autophagy Lysosomal Pathway and

Neurodegeneration

Steven Finkbeiner

Functional Modules of the Proteostasis Network Gopal G. Jayaraj, Mark S. Hipp and F. Ulrich Hartl

Protein Solubility Predictions Using the CamSol Method in the Study of Protein Homeostasis Pietro Sormanni and Michele Vendruscolo

Recognition and Degradation of Mislocalized

Proteins in Health and Disease

Ramanujan S. Hegde and Eszter Zavodszky

The Nuclear and DNA-Associated Molecular Chaperone Network

Zlata Gvozdenov, Janhavi Kolhe and Brian C. Freeman
The Amyloid Phenomenon and Its Significance in Biology and Medicine

Christopher M. Dobson, Tuomas P.J. Knowles and Michele Vendruscolo

A Chemical Biology Approach to the Chaperome

in Cancer--HSP90 and Beyond

Tony Taldone, Tai Wang, Anna Rodina, et al.

Proteostasis in Viral Infection: Unfolding the Complex Virus-Chaperone Interplay Ranen Aviner and Judith Frydman

The Proteasome and Its Network: Engineering for Adaptability Daniel Finley and Miguel A. Prado

Functional Amyloids Daniel Otzen and Roland Riek

Chaperone Interactions at the Ribosome Elke Deuerling, Martin Gamerdinger and Stefan G. Kreft

Mechanisms of Small Heat Shock Proteins Maria K. Janowska, Hannah E.R. Baughman, Christopher N. Woods, et al.

Structure, Function, and Regulation of the Hsp90 Machinery

Maximilian M. Biebl and Johannes Buchner

For additional articles in this collection, see http://cshperspectives.cshlp.org/cgi/collection/

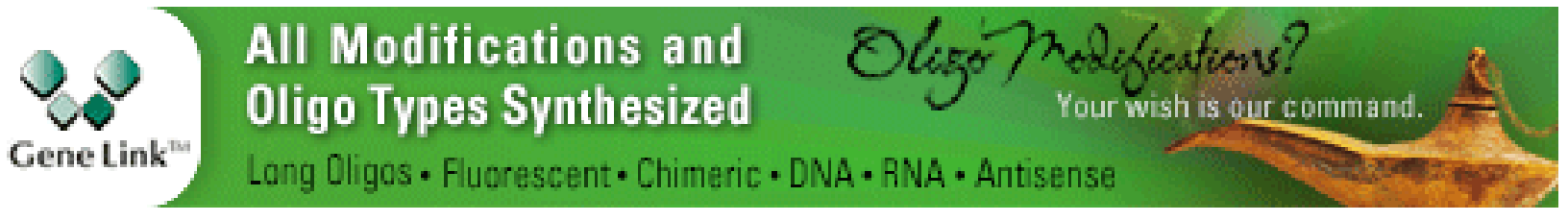


For additional articles in this collection, see http://cshperspectives.cshlp.org/cgi/collection/

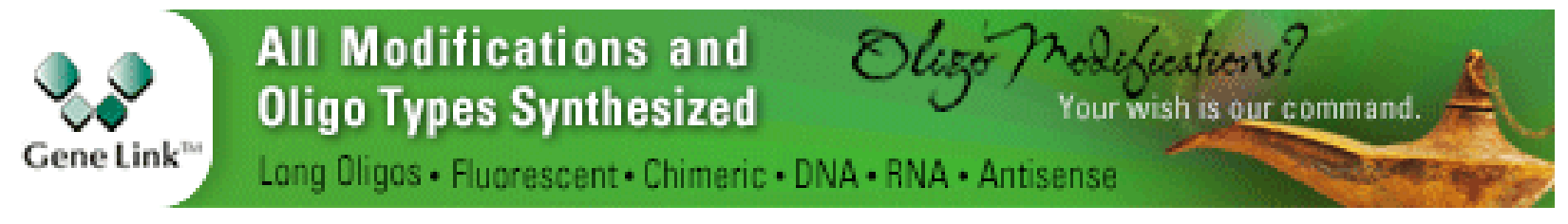

Copyright @ 2020 Cold Spring Harbor Laboratory Press; all rights reserved 